\title{
Integration of ICT-Pedagogy for Senior High School Students: Pre-service Teachers' TPACK (Technological Pedagogical Content Knowledge)
}

\author{
Fatahillah Erfan', Sulisyaningsih $^{2}$, Abd. Syakur ${ }^{3}$ \\ ${ }^{1,2,3}$ STKIP PGRI Sidoarjo, Indonesia \\ fatahillaherfan@gmail.com, sulistyaningsih3112@gmail.com,syakurabdmpd@gmail.com
}

\begin{abstract}
This study aimed to identify pre-service teachers who are ready to integrate technology into their classrooms. The assumption is that pre-service teachers' characteristics like Technological Pedagogical Content Knowledge (TPACK) are influenced by their teacher training. Preservice teachers were clustered based on their TPACK, a typical set of ICT-related characteristics (general ICT attitudes, attitudes towards ICT in education, ease of use and ICT self-efficacy), and perceived support from their training institution. A random sample of 50 senior high school pre-service teachers from SMA Al-Iftitahiyah in Sumenep was used in this mixedmethod research. The results also showed that most participants understood TPACK and had ideas for implementing it in their classrooms. Pre-service teachers' (PTs) perceptions of TPACK in teaching and learning is expected. This study also has implications for experts interested in pre-service teachers' understanding of teaching with technology.
\end{abstract}

Keywords

technology integration; ICT; pedagogy; TPAK

\section{Introduction}

In the development of the world of education, especially after the rolling reforms, new phenomena have arisen in educational institutions, which are schools that use the term Integrated Islamic Schools (Titik, 2010: 42). The school is essentially aimed at helping parents teach good habits and add good character, also given education for life in society that is difficult given at home. Thus, education in schools is actually part of education in the family, which is also a continuation of education in the family (Daulay in Ayuningsih, W. et al. 2020).

The introduction of modern technology into classrooms has piqued the interest of educators and students alike in the development of technology integration into instruction in order to provide students with a higher-quality education. Recognizing the significance of information and communication technology (ICT) in education, teachers should make use of the technology to assist students in achieving their objectives and in understanding and applying the concepts of ICT more effectively. Individual intellectual skill in mathematics has been demonstrated to be developed through the use of information and communications technology (ICT), which is a prerequisite for not only individual prosperity in this information explosion, but also for the development of national education policy (Oldknow \& Taylor, 2000).

Today's school teachers are dealing with a new generation of students who have grown up with new technologies as omnipresent tools in their daily lives. The changes have occurred at a rate that could not have been predicted two or three decades earlier (Spector, 2010). However, increasing access to technology does not appear to be sufficient to result in the effective use of technology in education, such that teachers play a key role 
in enhancing student learning through the use of technology-enhanced classroom practices, as previously stated. Teaching future teachers to integrate technology into their educational practices is, as a result, an increasingly difficult challenge that teacher training institutions (TTI) are being faced with (Liu, 2016). TTIs must assist pre-service teachers in bridging the gap between technology, pedagogy, and content knowledge in order to effectively train them (TPACK).

A theoretical framework for understanding the knowledge required by teachers for effective technology integration, Technological Pedagogical and Content Knowledge (TPACK), was introduced to the field of educational research in the 1990s (Koehler \& Mishra, 2009). To effectively integrate technology into education, according to Koehler and Mishra (2009), teachers must be proficient in these three types of knowledge, but more importantly, they must be able to integrate all three types of knowledge (Sang, Tondeur, \& Chai, 2014). TPACK emphasizes the importance of preparing pre-service teachers to make informed decisions about how they will use technology when teaching specific content to a specific target group, as well as how they will use technology in general. Teachers will be able to engage and motivate students as they explore the content of academic fields to a greater degree for educational goals if they have a proper TPACK. According to the TPACK framework, integrated knowledge of technology, pedagogy, and content is required for effective and innovative classroom teaching with technology (Abbitt, 2011).

The TPACK Model is based on a model developed by Shulman (1986) that explains how teachers' understanding of Knowledge and Technology interact with one another in the creation of effective teaching practices. It is generally defined as knowledge developed through the knowledge base, which is a synthesis of three types of knowledge: content knowledge, pedagogy knowledge, and context knowledge. Mishra and Koehler (2006) expanded on this concept by including a third set of Technology and Knowledge, resulting in \& TPACK. They are a content-based teaching and learning process that must make use of technological advances. This Model is depicted in Figure below by the TPACK diagram Venn.

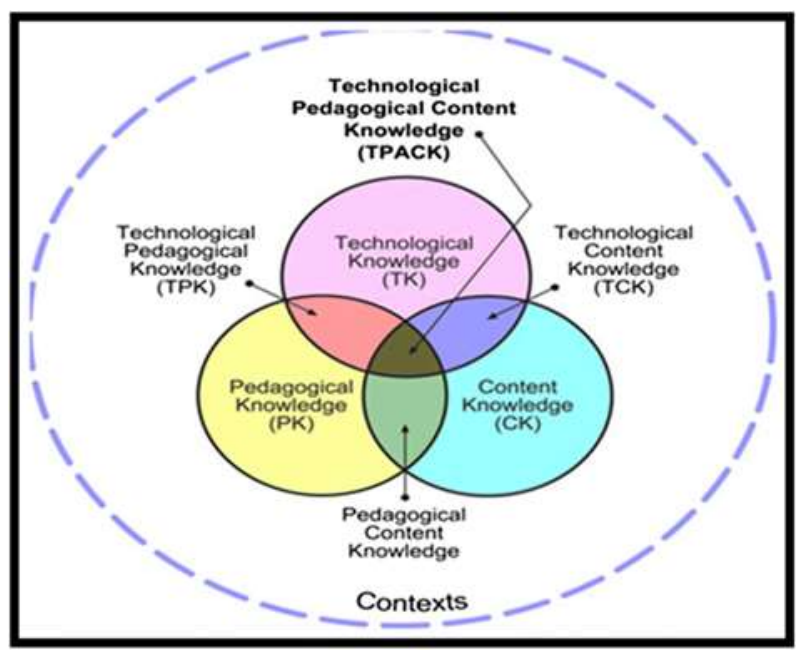

Figure 1. TPACK Model

Based on figure 1., it is illustrated that the TPACK not only constructed of three primary knowledge i.e., content knowledge, pedagogical knowledge and technology knowledge, but there are three more sets of their combined knowledge that are also 
considered to be important in the TPACK namely: pedagogical content knowledge (PCK), technological content knowledge (TCK) and technological pedagogical knowledge (TPK).

Today, technical issues such as school infrastructure and hardware, referred to as external barriers, have been overcome, and teachers' and students' access to technology has improved. However, it does not appear that teachers will be able to incorporate this technology into the classroom. Even experienced teachers, despite possessing the necessary ICT skills, lack the necessary competence to integrate ICT into the teachinglearning process (Aslan \& Zhu, 2015). There is a need for teachers' knowledge, beliefs, and attitudes toward ICT integration to change. A multifaceted approach is required to address internal barriers, including teacher competencies (Nelson \& Hawk, 2020).

Niess (2015) discovered that TPACK is highly personal, and that in order to understand pre-service teachers' TPACK, several individually and perception-based characteristics of their ICT profiles must be studied. In this section, we examine the literature to determine the significance of pre-service teachers' characteristics related to educational ICT use and how this can be related to their TPACK. However, this list of factors does not capture the full complexities of characteristics. This paper's knowledge base is by no means definitive or exhaustive. Understanding one element necessitates understanding the foundation on which that element is built, which can lead to the discovery of other significant elements.

Teachers should use their ICT knowledge and skills in teaching and learning processes, according to latest studies (Angeli \& Valanides, 2009). Even after taking instructional technology courses, Hew and Brush (2007) discovered that student teachers had very little knowledge of effective technology integration. Teachers are expected to have digital skills and competencies to use effectively in the teaching-learning process because of the changing nature of technology in the classroom. As a result, the goal of this research was to discover how pre-service teachers conceptualize and implement TPACK in the classroom. Researchers collect data from a representative sample of the general population using a survey they design themselves. In general, the results of this research show that the majority of participants have a solid grasp of the TPACK concept, as well as the benefits and drawbacks of implementing it in the classroom.

This study was conceptualized in this context. Pre-service teachers were expected to have acquired technological, pedagogical, and content knowledge as a result of their knowledge and experiences gained from various content, theories, methods/strategies, and field study courses. Though technology courses provided a variety of technological tools as well as opportunities to learn and practice technical skills, it was emphasized that mere exposure to a number of ICT tools does not guarantee that pre-service teachers will develop the skills necessary to design successful, technology-integrated lessons (HyoJeong \& Bosung, 2009). Fathi \& Yousefifard (2019) used a TPACK scale questionnaire to assess Iranian EFL students' perspectives on their teachers' TPACK. However, in contrast to many previous studies, the majority of which used interviews and the TPACK questionnaire to collect data from participants, this mixed-method research used interviews and questionnaires to collect data from them. These setbacks in the foreign context prompted the researchers to look into the current state of ICT integration among Senior High School pre-service teachers at SMA Al-Iftitahiyah in Sumenep, East Java, Indonesia.

\section{Research Method}

The purpose of this study is to investigate the Senior High School pre-service teachers at SMA Al-Iftitahiyah in Sumenep in order to gain their understanding of TPACK 
and to examine how they apply TPACK in their classroom. To accomplish this goal, a TPACK questionnaire was created, and an online survey of pre-service teachers' perceptions of TPACK was conducted using Google Form. Data for this mixed-methods study were gathered from 50 pre-service teachers at this Senior High School.

The TPACK technology-dimensions (TCK, TPK, TPCK, and TK) were measured using an adapted questionnaire from Dutch version of Schmidt et al. (2009). Teacher students were asked to indicate how much they agreed with a number of statements about The technology-dimensions $(0=$ completely disagree, $4=$ completely agree $)$. This new tool revealed a general TPACK (TPCK, TPK, and TCK) was measured by 14 items that tapped TPCK, TPK, and TCK (Cronbach's =.875).

\section{Discussion}

The primary goal of this study was to identify pre-service teacher profiles in order to investigate their readiness to integrate technology into teaching and learning activities. Based on their TPACK, other individual ICT-related characteristics, and perceived support from their teacher training institution, two profiles were identified: (1) the high educational ICT profile (H-ICT) and (2) the low educational ICT profile (L-ICT). All individual characteristics (e.g., general ICT attitudes, attitudes toward the use of ICT in education, self-efficacy, and TPACK) were positively correlated in both profiles. This finding is consistent with previous research indicating that general and domain-specific attitudes toward the use of ICT in education are closely related (cf. Agyei \& Voogt, 2015). Another general finding was that (pre-service) teachers who had more positive attitudes toward ICT in education were more likely to report positive attitudes toward ICT in education (see also Tondeur, Van de Velde, Vermeersch, \& Van Houtte, 2017). Surprisingly, pre-service teachers' ICT self-efficacy, ease of use, and TPACK are all associated with both profiles. Based on the data examined, the descriptive statistic of the T-dimensions measured could be seen on the following table:

Table 1. Descriptive Statistics and Reliabilities of the T-Dimensions Measure Technological Pedagogical Content Knowledge (TPACK)

\begin{tabular}{|c|l|c|c|}
\hline \multicolumn{1}{|c|}{ Item } & \multicolumn{1}{|c|}{ Wording } & Mean & SD \\
\hline TPACK 1 & $\begin{array}{l}\text { I am capable of delivering lessons that } \\
\text { effectively combine technology, literacy, and } \\
\text { teaching methods. }\end{array}$ & 2.48 & 0.82 \\
\hline TPACK 2 & $\begin{array}{l}\text { I am aware of ICT applications that can be used } \\
\text { to supplement the subject I teach. }\end{array}$ & 2.62 & 0.76 \\
\hline TPACK 3 & $\begin{array}{l}\text { I can select ICT applications to support lessons } \\
\text { in a specific subject domain. }\end{array}$ & 2.78 & 0.72 \\
\hline TPACK 4 & $\begin{array}{l}\text { I understand how to use ICT applications to } \\
\text { present concepts from a discipline to my } \\
\text { students in a creative manner. }\end{array}$ & $\mathbf{2 . 6 0}$ & $\mathbf{0 . 7 6}$ \\
\hline
\end{tabular}


Table 1. Shows the overall average score that is TPACK with $\mathrm{M}=2.60(\mathrm{SD}=.76)$ which is at a moderate level. It means that teachers are very knowledgeable about their fields' technology knowledge, content knowledge, pedagogical knowledge, pedagogical content knowledge, technological pedagogical knowledge, technological content knowledge, and technological pedagogical content knowledge, but they are unable to deliver their knowledge about the seven components of technological pedagogical content knowledge in a way that allows students to gain a better understanding. The items' overall mean was 2.60, with a descriptive rating of "High proficiency" and a standard deviation of 0.76. According to these findings, respondents' perceived knowledge of pedagogies and teaching practices was adequate. This, according to Aquino (2015), can also be attributed to having professional subjects that covered the preparation, use of various methods and strategies to teach a specific content area.

The general attitudes toward ICT scale (Cronbach's =.86), a 5-item scale developed by Evers, Sinnaeve, Clarebout, van Braak, \& Elen (2009), was the first instrument used to assess pre-service teachers' attitudes. It includes items relating to interest (e.g., "I want to know more about computers"), pleasure (e.g., "I like to talk about computers to other people"), and usefulness (e.g., "I use a computer because it is useful to me"). The ease-ofuse scale (Cronbach's =.82) has three items (for example, "I feel comfortable using computers"). The attitudes toward ICT in education scale (Evers et al., 2009) assesses students' attitudes toward the effects of using computers in education across four dimensions: interest, ease of use, pleasure, and usefulness. The eight items on pre-service teachers' self-efficacy (Cronbach's $=.85$ ) assess the degree to which pre-service teachers believe they are competent to use ICT as a supportive tool to strengthen their instructional practice (Tondeur et al., 2017), such as "select ICT applications in light of a specific educational setting" or "design a learning environment with the available infrastructure". Respondents were asked to rate each statement on a 4-point Likert scale, with 0 indicating strongly disagree and 4 indicating strongly agree.

In regard to TPACK, this domain was regarded as the nexus of all three bodies of knowledge. Understanding of this knowledge may go beyond understanding technology, content, or pedagogy in isolation, but rather as an emergent form that comprehends how these forms of knowledge interact with one another (Koehler and Mishra, 2008). The overall mean for TPCK was 3.07, with a descriptive rating of "Agree (High proficiency)" and a standard deviation of 0.42 . All of the items in this domain received a descriptive rating of "Agree", indicating that respondents were confident in their ability to perform well in this domain. According to Aquino (2015), the way pre-service teachers perceived the interrelationship of content, pedagogy, and technology led to their confidence in selecting and implementing technologies that would improve their teaching and learning of a specific content or topic. This could be related to their classroom learning experiences.

In terms of ICT integration in classroom instruction, the results of classroom observations and lesson artifact analysis during the student teaching program. During the actual demonstration, the researcher used the "Technology Integration Observation Instrument" developed by Hofer et al. (2011) to generate quantitative data from observations. The overall mean of pre-service teachers' ICT integration in classroom instruction was 3.06 , with a standard deviation of 0.36 , implying that the majority of the observed lessons were rated as "good". Based on the data gathered, the majority of respondents were found to have chosen technologies that were aligned with one or more curriculum goals listed on their lesson plans. The alignment of curriculum goals and technologies was described as "good" with a mean of 3.18. 
Furthermore, all respondents agreed that learning a lesson integrated with technology was a good idea. "I incorporated technology in this lesson because listening to the audio recorder helped my students understand our lesson," one respondent argued. Aside from that, it's a way to encourage them to listen to and participate in our discussion." It is also worth noting that the majority of respondents revealed that the materials they used in the implemented lesson (e.g., pictures in the presentation, video presentation) were obtained from other sources (e.g., internet-based materials, downloaded files).

Other respondents used self-created materials, while others combined self-created materials with materials obtained from other sources. Some respondents customized and modified materials obtained from other sources. "I searched for a video on YouTube and edited it a little," one respondent explained. "Audio clips are downloaded from YouTube," said another participant. Respondents were also asked about the activities or exercises they planned for using technology to teach their lesson. The majority of respondents (22 or $44 \%$ ) used technology for presentation and illustration, interactive activities (9 or $22.5 \%$ ), and listening activities involving audio materials ( 8 or $20 \%$ ).

Based on the two profiles, it is clear that some pre-service teachers are intrinsically motivated to use ICT in their educational practice, whereas others are not (e.g., Teo \& Milutinovic, 2015). As a result, many researchers have cantered educational change processes on the individual teacher (Stoll, 1999). The findings of this study point to a link between TPACK and SQD. Preservice teachers who fit the profile of relatively positive attitudes, self-efficacy, and TPACK score higher on perceived support from their teacher training institution. As a result, understanding pre-service teachers' ICT profiles is critical in assisting pre-service teachers with ICT integration in education. TTIs play an important role in providing opportunities for pre-service teachers of both profiles to learn and build their TPACK. Clearly, these L-ICT pre-service teachers report less perceived support from their TTI. As a result, measuring pre-service teachers' ICT profiles can be viewed as an evaluation through which TTIs can adjust the support required to prepare future teachers for meaningful ICT integration in education. Furthermore, our study shows that TTIs matter for pre-service teachers' overall ICT profiles, despite the fact that the direction of causality cannot be described.

The findings of this study are similar to those of Pamuk et al (2013), who discovered a positive correlation between technological knowledge (TK) and technological content knowledge (TCK) and technological pedagogical knowledge (TPK); pedagogical knowledge (PK) with TPK and PCK; content knowledge (CK) toward TCK and PCK; and TK, CK, PK TCK, TPK, and PCK toward technological pedagogical content knowledge (TPACK). The findings are also consistent with those of Chai et al. (2010), who discovered that technological knowledge, pedagogical knowledge, and content knowledge were all significant predictors of TPACK.

Furthermore, the participants who stated that they still need to improve in order to use these types of collaboration tools, and there is only $2 \%$ (1 participant) who assumed that he uses the collaboration tools without a problem. The results of this chart show that, while the majority of participants can use collaborative tools in their classroom teaching, there is still room for improvement in using these tools in classroom teaching. There are numerous advantages to using technology in the classroom. This statement is consistent with a study that found that the main benefits of using technology for language learning are increased exposure to authentic language, access to a diverse range of information sources and language variations, opportunities for interaction and communication, and more intensive learner involvement (Carrió-Pastora \& Hanna Skorczynskab, 2014). 
We could tell from the three participants that there is a misunderstanding of the concept of TPACK. According to Mishra and Koehler (2006), TPACK is a framework for developing new learning models that evaluates three major aspects: technology, pedagogy, and content/material knowledge. Participants were also polled on their thoughts on the integration of technology in the classroom in this age of globalization. The majority of participants agreed that there is a need to integrate technology into the school to support students' learning. For example, because of the globalization era, it is recognized that technology is essential in the learning process. "It's critical because, in this globalization era, most of the segment of life is now integrated into the technology itself, especially in education, because many platforms of education are now raising that could be implemented in the classroom," it is stated. This finding is consistent with the findings of Chuang et al. (2018), who discovered that students improved in their Technological Knowledge when their teachers' used technology in the learning process. However, according to one participant, a technology-based educational platform has the potential to reduce classroom interaction.

According to the interview data, the majority of participants $(80 \%)$ use technology to support students' individual needs. One of respondents, on the other hand, assumed that she only needed an interactive classroom activity to meet the individual needs of her students. This interview session also included questions about how they use technology in the classroom. It is discovered that all participants have their own way of incorporating technology into the educational sector, particularly in the school. She also argued that sometimes the materials in the book are still incomplete, so to fill in the gaps, he provides materials from the internet, which he then incorporates into the PowerPoint slides. PSTs' technology knowledge self-efficacy, according to Simşek \& Yazar (2018), is an important variable influencing technology integration. In this study, the ICT competencies and TPACK competencies that perceive their abilities as proficient in terms of ICT use differ significantly. This study demonstrates that PSTs' computer ownership has a significant impact on their education; it allows them to improve their technological skills and is beneficial in terms of ICT integration competencies.

The discussion about how to better prepare pre-service teachers for TPACK should be seen as part of the overall development of the teacher education program, and technology should be infused as a systemic and systematic process throughout the entire teacher training program. Several authors also argued that pre-service teachers should collaborate in groups and actively participate in the research and design of tangible, meaningful ICT-related curriculum materials as end products of the learning process (Lee \& Lee, 2014). Many studies have shown that group work can help pre-service teachers with low ICT profiles overcome feelings of insecurity when designing technology-related curriculum materials (Angeli \& Valanides, 2009). In this regard, the current study's findings can be used to create group compositions based on profiles, as this can influence how positive the experience was perceived to be (Jang, 2008). Their research also suggests that changing the composition of working groups over time may have some advantages. Finally, research on TPACK (e.g., Koehler \& Mishra, 2009) suggests that allowing design teams to create technology-enhanced curriculum materials is a promising strategy for teachers. Pre-service teachers can share their attitudes and abilities with one another through collaboration. 


\section{Conclusion}

The current study added value by providing a more detailed account of how TPACK and a typical set of determinants of ICT integration can be associated within the profile of pre-service teachers. To guide future teachers in the development of TPACK and educational technology use, future teachers need a better understanding of their educational ICT profile. TTIs should carefully consider their pre-service teachers, recognize their ICT profiles, and consider their background when preparing them for twenty-first-century learning environments with new technologies. The study's findings are as follows: the majority of respondents reported that their TPACK components were moderate, and there are significant relationships between TPACK components. According to the findings, senior high school pre-service teachers at SMA Al-Iftitahiyah in Sumenep are expected to improve their knowledge of technological pedagogical content. Furthermore, primary school mathematics teachers must constantly balance the ability of technological pedagogical content knowledge components in order for classroom learning to be meaningful.

The static nature of the data used to develop the ICT profiles makes it difficult to understand the dynamic and evolving nature of preparing future teachers for educational technology use. Future research should therefore take an iterative approach to developing teacher profiles, with comparisons made over time. It would be interesting to see if TTI changes the profiles based on the stage of development. Future research should therefore take an iterative approach to developing (pre-service) teachers' ICT profiles. Finally, the TPACK profiles could be used as a determinant to assess how much ICT pre-service teachers actually use in their educational practice. These findings could be a good starting point for better preparing pre-service teachers for technology integration in the classroom.

\section{References}

Abbitt, J. T. (2011). An Investigation of the Relationship between Self-Efficacy Beliefs about Technology Integration and Technological Pedagogical Content Knowledge (TPACK) among Preservice Teachers. Journal of Digital Learning in Teacher Education, 27(4), 134-143. doi:10.1080/21532974.2011.10784670

Angeli, C., \& Valanides, N. (2009). Epistemological and methodological issues for the conceptualization, development, and assessment of ICT-TPCK: Advances in technological pedagogical content knowledge (TPCK). Computers \& Education, 52(1), 154-168.

Aslan, A., \& Zhu, C. (2015). Starting teachers' integration of ICT into their teaching practices in the lower secondary schools in Turkey. Educational Sciences: Theory \& Practice, 18(1), 23-45.

Ayuningsih, W. et al. (2020). Implementation of Islamic Education Curriculum Development in Al-Ulum Islamic School Medan. Budapest International Research and Critics in Linguistics and Education (BirLE) Journal. P. 1033-1044.

Koehler, M. J., \& Mishra, P. (2009). What is technological pedagogical content knowledge? Contemporary Issues in Technology and Teacher Education, 9(10), 6070.

Liu, S. H. (2016). Teacher education programs, field-based practicums, and psychological factors of the implementation of technology by pre-service teachers. Australasian Journal of Educational Technology, 32(3), 65-79. doi:https://doi.org/10.14742/ajet.2139 
Nelson, M. J., \& Hawk, N. A. (2020). The impact of field experiences on prospective preservice teachers' technology integration beliefs and intentions. Teaching and Teacher Education, 89, 1-12.

Niess, M. L. (2015). Transforming teachers' knowledge: Learning trajectories for advancing teacher education for teaching with technology. In Technological pedagogical content knowledge. 19-37.

Oldknow, A., \& Taylor, R. (2000). Teaching Mathematics with ICT. London: Continuum Press.

Sang, G., Tondeur, J., \& Chai, C. S. (2014). Validation and profile of Chinese pre-service teachers' technological pedagogical content knowledge scale. Asia-Pacific Journal of Teacher Education, 1(17), 49-65.

Spector, J. M. (2010). An overview of progress and problems in educational technology. Interactive Educational Multimedia, 1, 27-37. 